\title{
IoTSAMS: A Novel Framework for Internet of Things (IoT) Based Smart Attendance Management System
}

\author{
Farzana Akter, Amatul Bushra Akhi, Nusrat Jahan Farin, Md. Mohsin Khondoker, \\ Md. Golam Saklayen \\ Department of Computer Science and Engineering, Daffodil International University, Dhaka, Bangladesh \\ Email: farzana.cse@diu.edu.bd, akhi.cse@diu.edu.bd,nusratfarin89@gmail.com,mohsin15-138@diu.edu.bd, \\ golam3682@diu.edu.bd
}

How to cite this paper: Akter, F., Akhi, A.B., Farin, N.J., Khondoker, Md.M. and Saklayen, Md.G. (2018) IoTSAMS: A Novel Framework for Internet of Things (IoT) Based Smart Attendance Management System. Intelligent Control and Automation, 9, 74-84

https://doi.org/10.4236/ica.2018.93006

Received: June 8, 2018

Accepted: August 14, 2018

Published: August 17, 2018

Copyright $(9) 2018$ by authors and Scientific Research Publishing Inc. This work is licensed under the Creative Commons Attribution International License (CC BY 4.0).

http://creativecommons.org/licenses/by/4.0/

\begin{abstract}
Automated attendance management system will reduce complexity by eliminating plenty of manual processes involved in attendance system and calculating hours attended. This paper presents a simple technique of taking student attendance in the form of an Internet of Things (IoT) based system that records the attendance using fingerprint-based system and stores them securely in a database. We use NodeMCUV3, RFID Module and Fingerprint sensor module in our system. The fingerprint module is responsible for authentication of the students. RFID Module is used to scan the RFID tag and sends data to the central server. By using this information, the system will generate an attendance report which can be accessed for further use.
\end{abstract}

\section{Keywords}

Automated Attendance, Arduino, Fingerprint Module, IoT, RFID Tag and Reader

\section{Introduction}

The Internet of things (IoT) refers to a network infrastructure of physical devices and some other items which are integrated with electronics, software, sensors, actuators and network connectivity. This incorporates everything from cellphones, coffee machines, dish-washers, earphones, lights, wearable gadgets and just about whatever else anybody can consider. These connected objects collect and exchange data among each other via the communication medium. The main goal is to avoid human intervention by allowing the objects to be sensed by the 
sensor or to be controlled remotely across the existing communication network for connecting the physical world to the computer based system with the aim of improved efficiency, more accuracy and economic benefit. Several applications have been developed using IoT in recent years including automated monitoring of Parking spaces available in the cities, Sound monitoring in bar areas and centric zones in real time, Monitoring of vehicles and pedestrian levels to optimize driving and walking routes, Intelligent and weather adaptive lighting in street lights, Detection of rubbish levels to optimize the trash collection routes, Control of $\mathrm{CO}_{2}$ emissions of factories, pollution emitted by cars and toxic gases generated in farms etc. According to various researches that have been made, it is predicted that IoT will spread rapidly over the upcoming years. By 2020 the amount of data collected from connected devices could reach to 50 trillion gigabytes. The Gartner prediction show that connected devices will experience an upward trend of 25 Billion by 2020 and make in excess of 300 Billion US dollar revenue per annum in 2020 which will uncover new business opportunities. Attendance is a fundamentally important part of education. Educational institutions need an unfailing way of recording student attendance not only for tracing poor attendance record but also to support quality learning. The most traditional way of taking attendance in the classroom is by roll calling, ask the student to sign on a paper based attendance or card punch are highly troublesome and lead to an unnecessary time waste by teachers and administration. It is also very difficult to manage manual supervision of large number of students. Therefore this traditional method of student tracing cannot prevent proxy attendance, ID card theft and attendance tracing errors that have an outright effect of quality education. In this paper we will propose an automated student attendance system based on this newest technology called Internet of Things (IoT).

In this paper we have proposed architecture of an automated student attendance tracing system that will read a student's id number from the microchip integrated ID card they have used, using a sensor when he/she entered into the classroom and stores them securely over web. In Section 2 background study is described. Section 3 described the methods of the proposed system. Results and discussion is detailed in Section 4 and paper is concluded in Section 5.

\section{Background Study}

Automated Attendance system is very much helpful to eliminate the cumbersome process of manually taking and storing employee attendance records which saves time and money also. With the help of automatic attendance system, authority can track employee's time on the office more accurately and easily. Day by day different types of automatic identification system have launched for detecting attendance and maintain this information to make human resource management easier. The system like Smart Classroom Roll Caller System (SCRCS), IoT based RFID smart card system, GSM/GPRS based attendance system, IoT Based Biometric Attendance System etc. are present today. Reducing 
the rates of student absenteeism becomes an important managerial challenge in every level of education system. Less attendance can effect on both students as well as the learning environment of an entire university. Chang and ChingHisang (2011) [1] proposed a Smart Class-room Roll Caller System (SCRCS) which is installed at every classroom where HF/UHF readers mounted in classroom doorways and RFID tags attached to student ID card and the system can read the card and show total number of attendance on the LED display of SCRCS. After that the academic office will collect this information. Later biometric attendance system increases the efficiency of this process. Researchers further described a fingerprint based biometric scanner that is used to detect students and the system then store data securely in database. This reliable process solves the problem of proxy attendance. According to this system authority can sent attendance report to parents email to make concern among themselves about the less attendance of their children [2] [3].

Another concept is proposed by Prince where the student verification is done using R305 fingerprint module [4]. The finger print module receives student data and after successful recognition of fingerprint pattern this record is stored in the web-server. This data is sent by using the serial interface to the Arduino that provides a data sequence combined with student ID, teacher ID and device ID etc. so that the attendance cannot be forged. A Wi-Fi Module named esp8266-01 is used to send this information to the web-server where it will be decoded.

In IoT based face recognition system, a real time image of classroom will be captured using a web camera and then compare this detected image with those present in the database. An excel sheet is used to maintain this update. Kawaguchi developed the system to take attendance automatically using face detection [5]. The system use two types of cameras: the sensing camera and the capturing camera. The sensing camera is used to trace each bench in the classroom that instructs to move the capturing camera towards the students and captures images. Then systems store this information in database and detect the individual students. Subramaniam developed a Bar Code Scanner Based Student Attendance System (SAS) where the bar code scanner is used to scan the twelve digits of student identification number from the students ID card [6]. This information then sends to the database. Younis developed a scalable RFID-based attendance system with an intelligent scheduling technique named is (IAAS) [7]. Cho proposed a low cost system using Near Field Communication (NFC) [8].

An NFC tag was mounted on classroom desk. When a student touches this tag with their smartphone then their attendance was recorded by the system. Krishna, et al. [9] design an intelligent campus security tracking system (iCST) where they combined the RFID, ZigBee network and GSM(Global System for Mobile) to authenticate and store users information. The GSM is used to send a free voice call to the parents if the students are regularly absent in their class. Yadav, et al. proposed an automated fingerprint recognition system implemented by RTOS (Real time operating system) under the domain of embedded system [10]. 
There is a major drawback in fingerprint based attendance system. If fingers get roughed/scratched it leads to misreading by the device. Face recognition system is considered as a great solution of this kind of problem. There are also some problems occurs in this technology, image quality, image size, the relative angle of the targets face may affect the result. An-other important issue is if any student makes proxy illegally NFC based system is unable to detect it. In [11], researchers propose a method where they take attendance electronically using a fingerprint module and a Radio Frequency Identification module and the data were transferred into Raspberry Pi 2 Model initially. GSM module is used to send data to the parents as a message.

In this study, a relatively new system is proposed for monitoring individual's attendance automatically. Some sensor module used here such as fingerprint module, a RFID tag, RFID reader. To collect data from the module Arduino, a microprocessor, is used. Arduino is open source (hardware, software and IDE) and very feasible for real-time application [12]. There exists many systems those use raspberry pi as a communicator; however, it is not an open source and also costly [13]. Arduino is cheaper than raspberry pi and also perform better in repetitive tasks [14]. In this proposed system, a RFID tag is mounted on users ID card which can be read by RFID reader. Fingerprint module collects the fingerprint of the user. After collecting the data RFID reader is active for that particular ID. After that, RFID reader collects the data for those ID from RFID and sends the data to the server. In this way the proposed system is worked. The proposed system description is given below in detail.

In Figure 1, all universities of Bangladesh are denoted with a pie chart. Our survey shows that almost $80 \%$ universities are following the traditional manual paper pen based attendance system whereas only $12 \%$ are fully implementing the software based student attendance system as shown in Figure 1 with blue zone. Approximately $8 \%$ of the universities are using this partially.

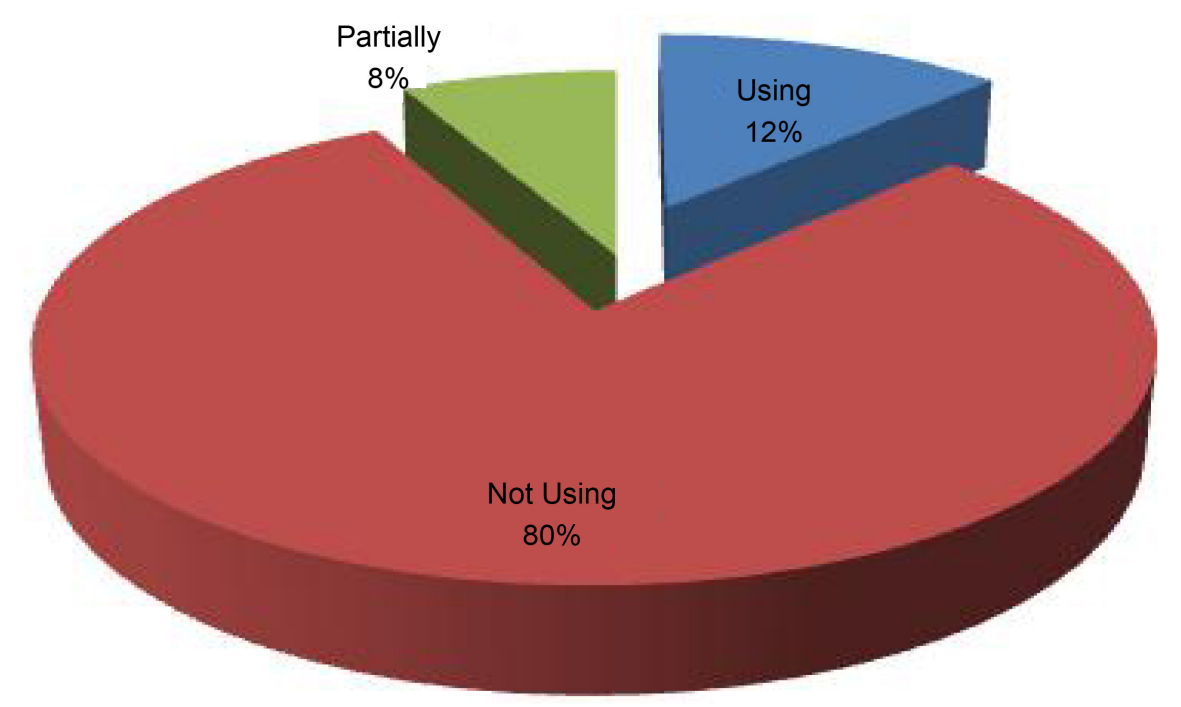

Figure 1. Automated attendance system usage in Bangladeshi university. 


\section{Methods}

The Proposed methodology is discussed in this section. Three layer are shown of this system is shown in Figure 2. These layers are central unit, classroom or working place, nodes or users. Nodes send data by the detector to the local server. By receiving the data local server sends data through application to the database using wifi module. The overview of the proposed model is detailed with Figure 2. Whole process of the proposed methods is described with he following subsections.

\subsection{Overview of the System}

The aim is to design a system for taking automated attendance and send data to the central database to save the record and inform the attendance status to the particular person. Figure 2 shows architecture of the proposed system. The Flowchart of the proposed system is described with Figure 3. This proposed system has mainly three different units. The unit of the proposed framework is as follows

1) Sensor Unit

2) Management Unit

3) Central unit

User contain sensor, management based unit (classroom) where a device is set to sense data from the user, and another unit is central unit. Sensor based unit collect the physiological data from the monitoring body and the management unit check the data whether it is verified or not and also send data to database for authenticated person. Central system store data to central database through an interface of application and show the status of the user. The management units is from either a local host network and detects data from user node and send them to database via Wi-Fi module through an application.

The sensor based unit is design as follows:

1) Portable and easier to carry

2) User friendly

3) Light weight and provide all information about user

On the contrary, the management unit is designed as follows:

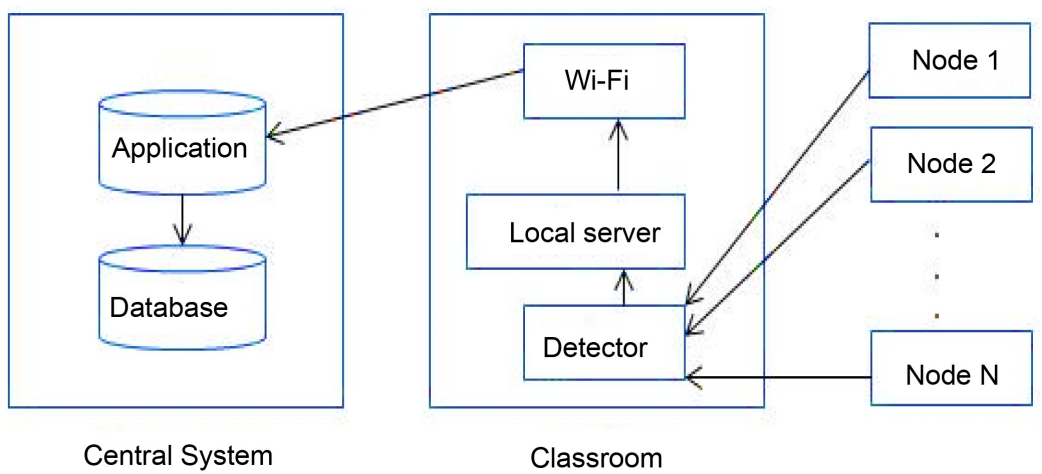

Figure 2. Overview of the proposed system. 


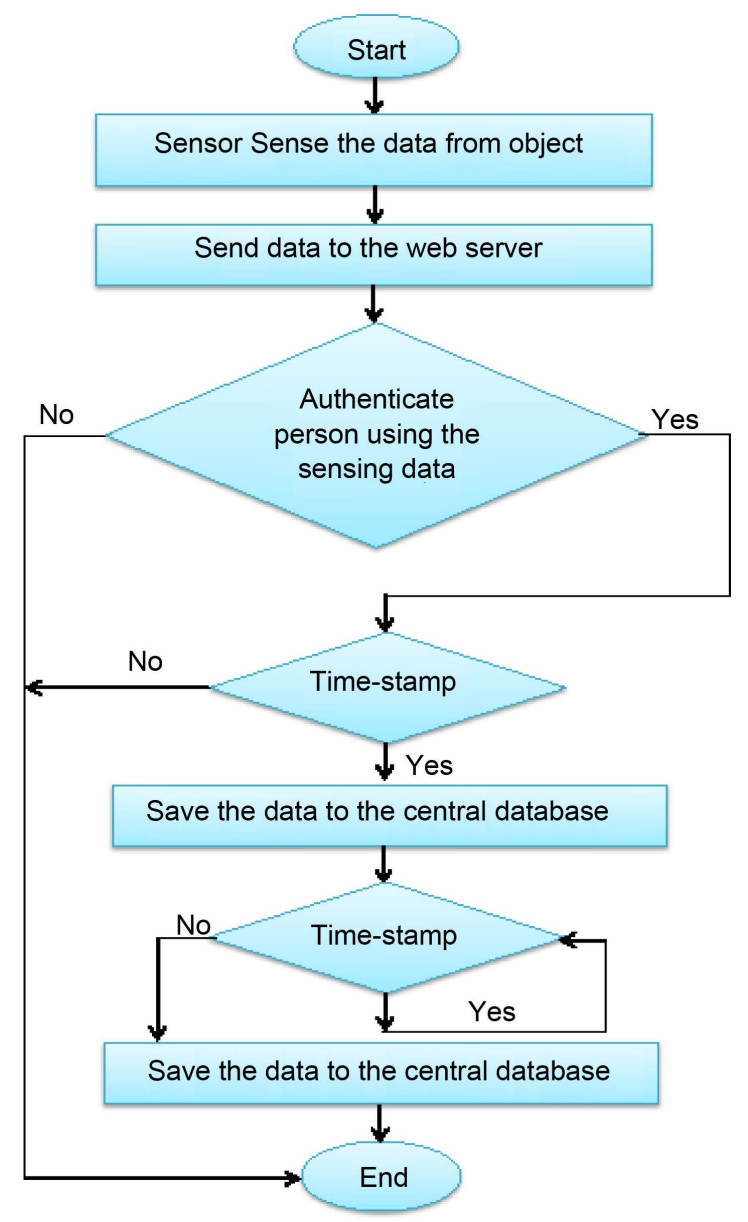

Figure 3. Flowchart of proposed system.

1) Sense data from user

2) Verified user

3) Send data to the central system for authenticated person via $\mathrm{Wi}-\mathrm{Fi}$

Central system is designed with application and central database. The central system designed is as follows:

1) Take data from management unit through an application

2) Save the authenticated data to the central database system

The transmission of data between a sensor node and the management unit is implemented by the client server model. Moreover, the management unit and the central system unit also transmit their data by client server model.

1) Sensor Based Unit. In this unit every node or user holds a chip to their identification card (ID). This card holds all the information about that particular student. Two sensors are used here to make the chip. One of them is used for holding the ID number and another is for authenticating particular user.

2) Management Unit. This unit does the main part of the proposed system. In this unit, data is collected from sensor unit. After collecting data the management unit authenticates the user of the system. If the user is verified then collected data will be sent to the central database via application. In case the user is 
not authorized to this system the data will not send to the central database system. Management unit manage the authenticating part of the system.

3) Central Unit: The proposed framework has a central unit which contains the central database and an application. Application helps to collect data and save to database. Central database used to save all the detailed data about individual attendance status.

\subsection{Architecture of the Proposed Prototype}

Figure 4 shows the architecture of the proposed system. The system comprises of several hardware components such as fingerprint module, a RFID card which integrated to identity card used by each students, detector device mounted on each classroom door with integrated NFC chip, central database server and internet to create an IoT infrastructure. All sensors and devices are connected with arduino. Details of the using module of this experiment are given to the followings.

1) Fingerprint Module: Fingerprint scanner being used to take fingerprint of students to authenticate the RFID card. Fingerprint scanner is connected to the network through arduino. It will take input fingerprint, process it and extract features of fingerprint for matching. After matching, system will enable the RFID card and update database attendance records.

2) RFID Module: RFID card is integrated with the ID card of each student.

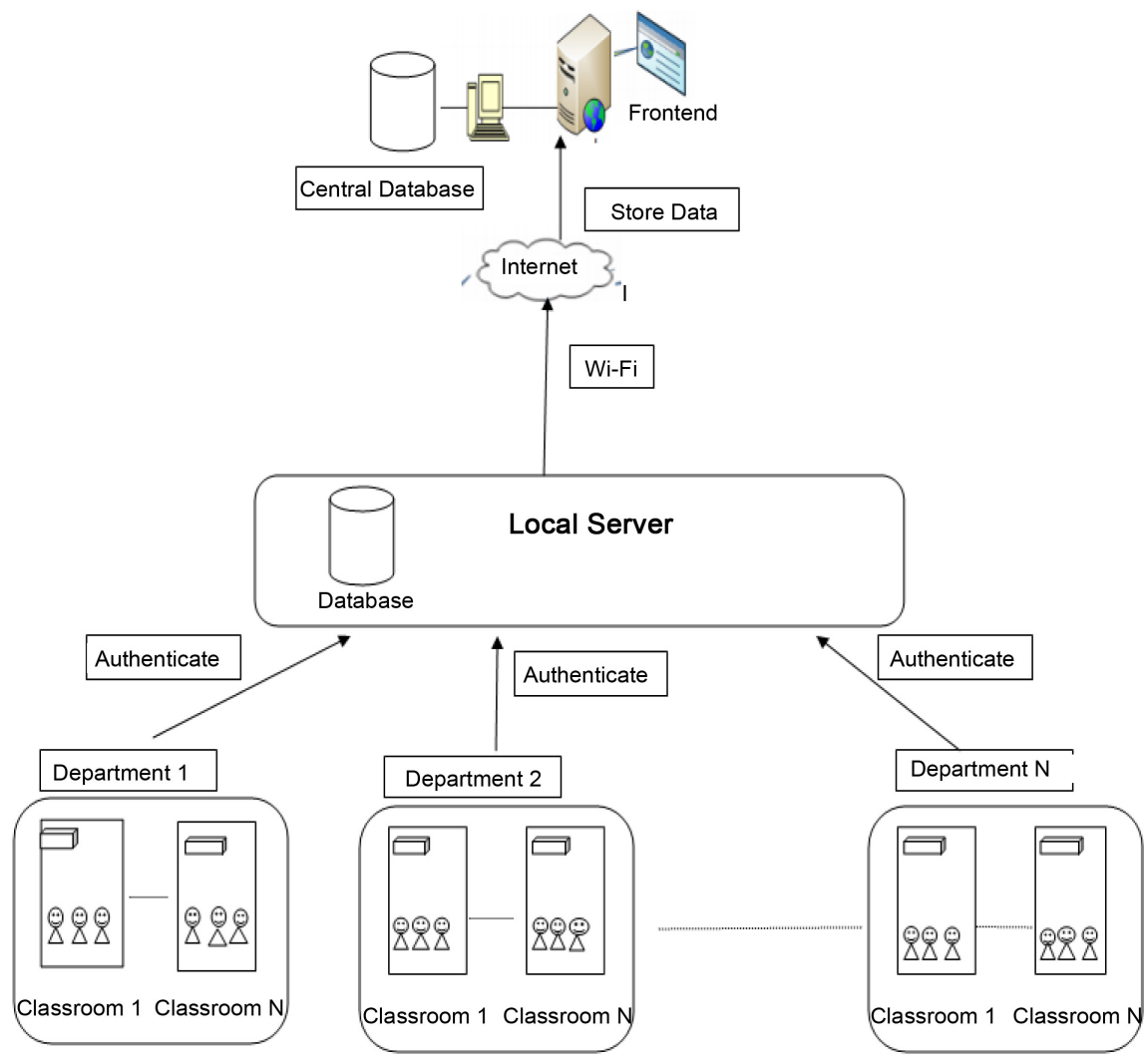

Figure 4. Architecture of the proposed framework. 
RFID reader is attached with the classroom's door.

3) Database Server. The database stores each record implemented in SQLite Server database. However, it may change to any other relational database. For sending the data to the server an interface is used. The interface is designed by PHP.

4) Network Service: The proposed system will be spread over a network from classrooms via intranet. Using this network, attendance will save to the database server. Then the system will generate the attendance report. This report can be print from the server. This system also provides the report to the course teacher, students and the university's authority over e-mail. Using this system, attendance could easily be maintained for students.

\subsection{Experiments}

The proposed system is IoT based smart attendance system (IoTSAMS) which is implemented with IoT such as arduino, finger module, RFID module. The server side system ran the apache, PHP language and SQL database and the sensors data read from the finger module and RFID module through arduino using arduino code. The implementation of the IoT based attendance system is described in this here. The environment of the experiment how the sensor and arduino board connected and how the system take attendance is shown in Figure 5.

\section{Results and Discussions}

To test the proposed prototype whether it works or not a classroom is selected with 40 students of Daffodil International University to take their automated attendance. This prototype can take the attendance and send it to the central database. The timestamp also worked properly. Two of them came after 15 minutes and the system took their attendance with late marks of 15 minutes and the system took their attendance with late marks of 15 minutes. The aim of this experiment is to identity the system's perfection. Figure 6 shows the database of

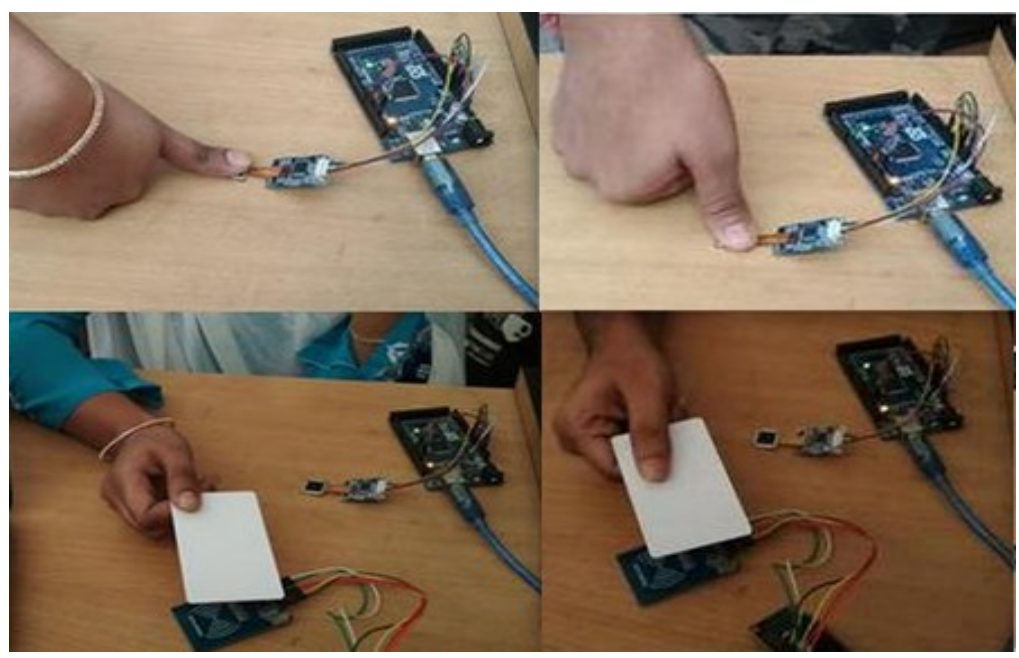

Figure 5. Experimental environment. 
(i) localhost/phpmyadmin/sql.php?server $=1 \& \mathrm{db}=$ attndnc $\alpha$ table $=$ presence $\alpha p o s=0$

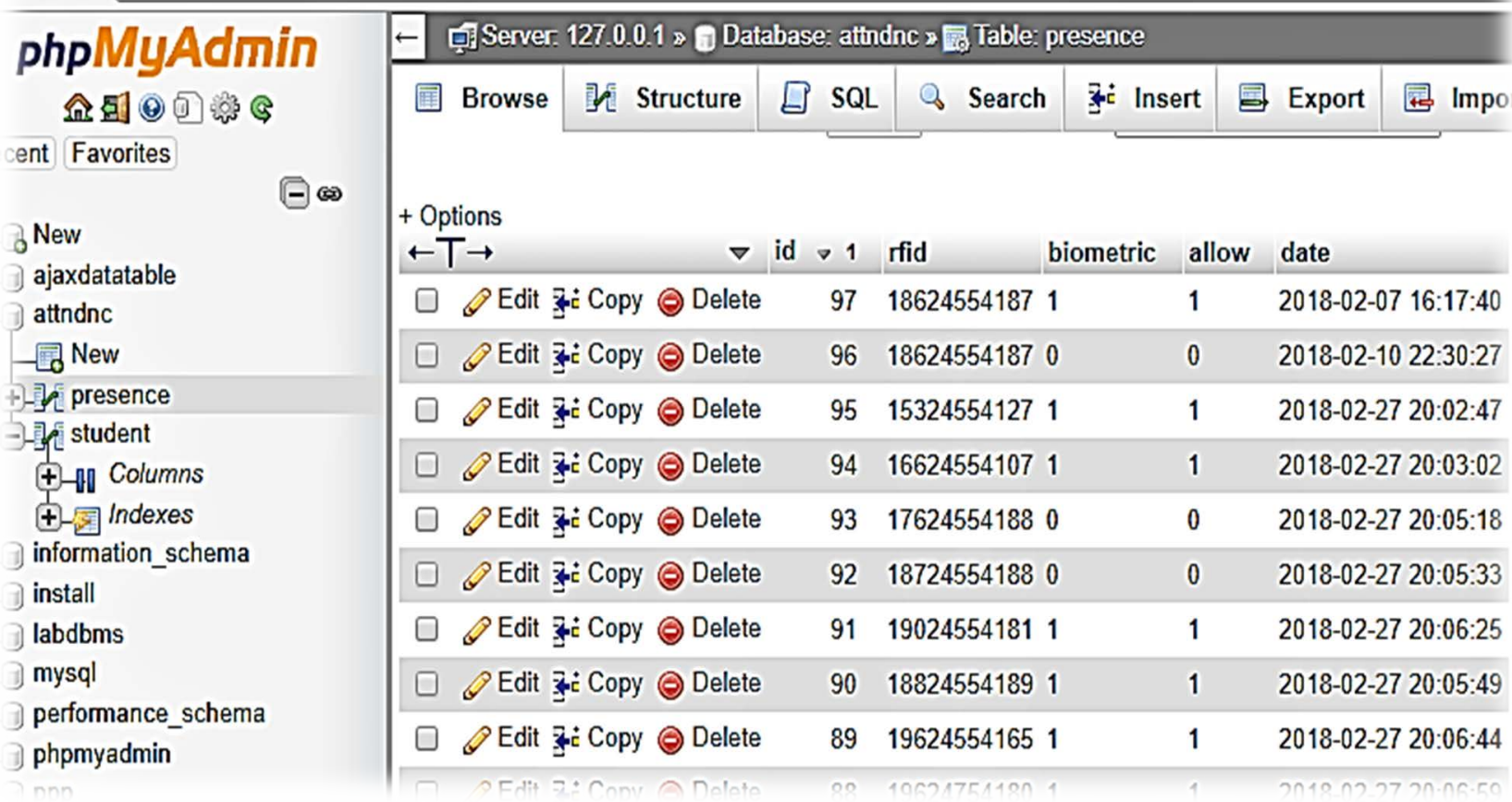

Figure 6. Smart attendance database.

student's attendance. In every situation (late or early) the system can mark the students and give their attendance to the corresponding courses. Figure 7 and Figure 8 show the output of the proposed prototype.

Many system is exists for automated attendance system. Every system has one layer security. So anyone can give proxy at any time. But in this proposed system the proxy rate is minimized because of double layered security system. Firstly, the system takes the fingerprint to make RFID reader enable for a particular ID. After the activation the reader can read the RFID for the specific time stamp. So, no one can give the proxy for the specific ID. No other system has the double layered security for the automated attendance system, this is the uniqueness of our proposed methodology.

\section{Conclusion}

This research proposes a model of a smart and automated student attendance system that has been designed to reduce the hassle of manual process. It has a great impact on the entire educational process. All teachers will be free from recording every individual student's attendance information that will save their valuable time and effort. All attendance related in-formation is accessible through the user interface for any administrative necessity. Besides that, the system will send the attendance information to the respective teachers, student as well as parents after the completion of each class. At the same time it will reduce the absent rate from $20 \%$ to $5 \%$ that will improve a student's performance. Thus our system will help in improvement of quality education. 


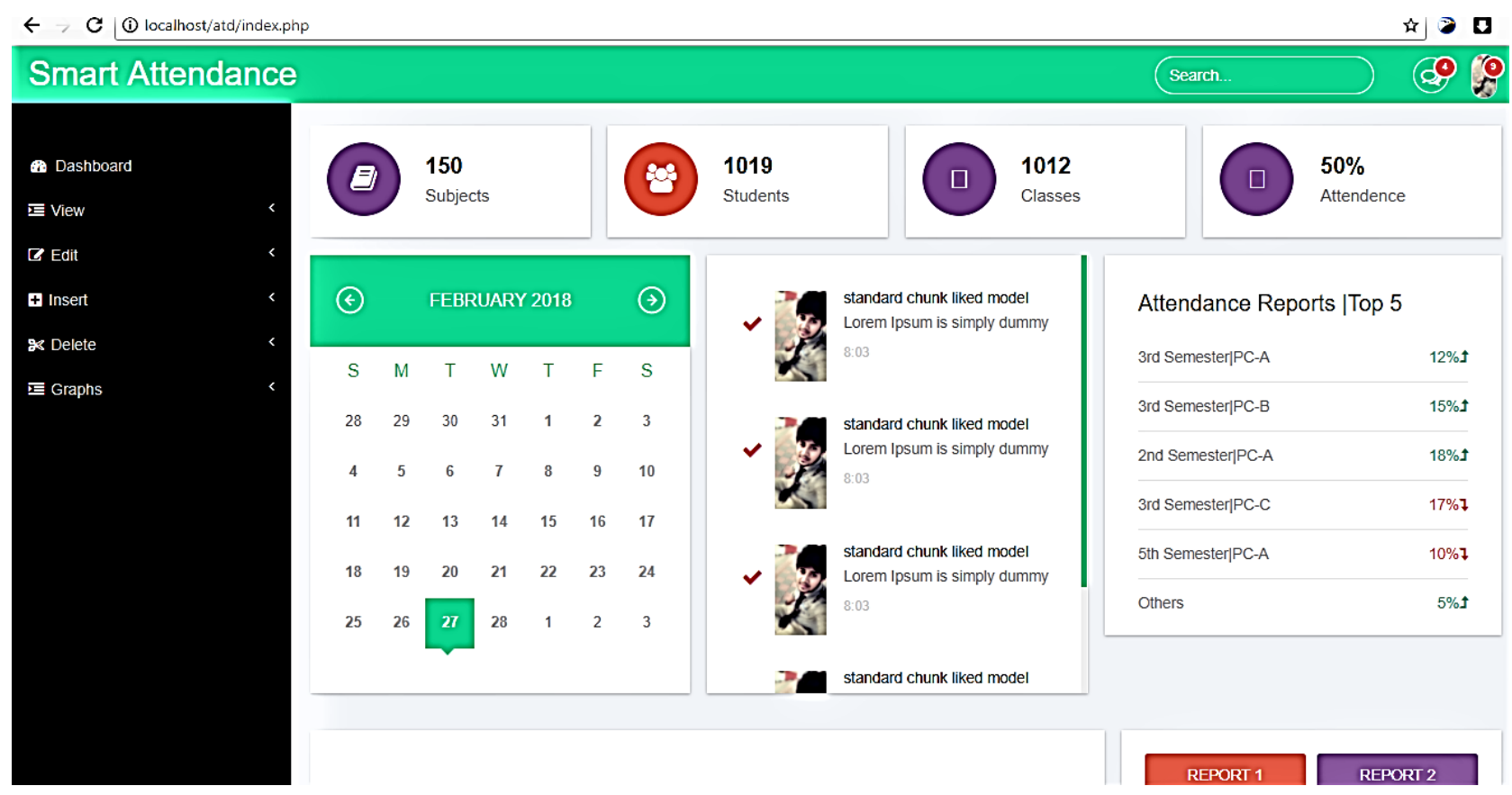

Figure 7. Report of the attendance.

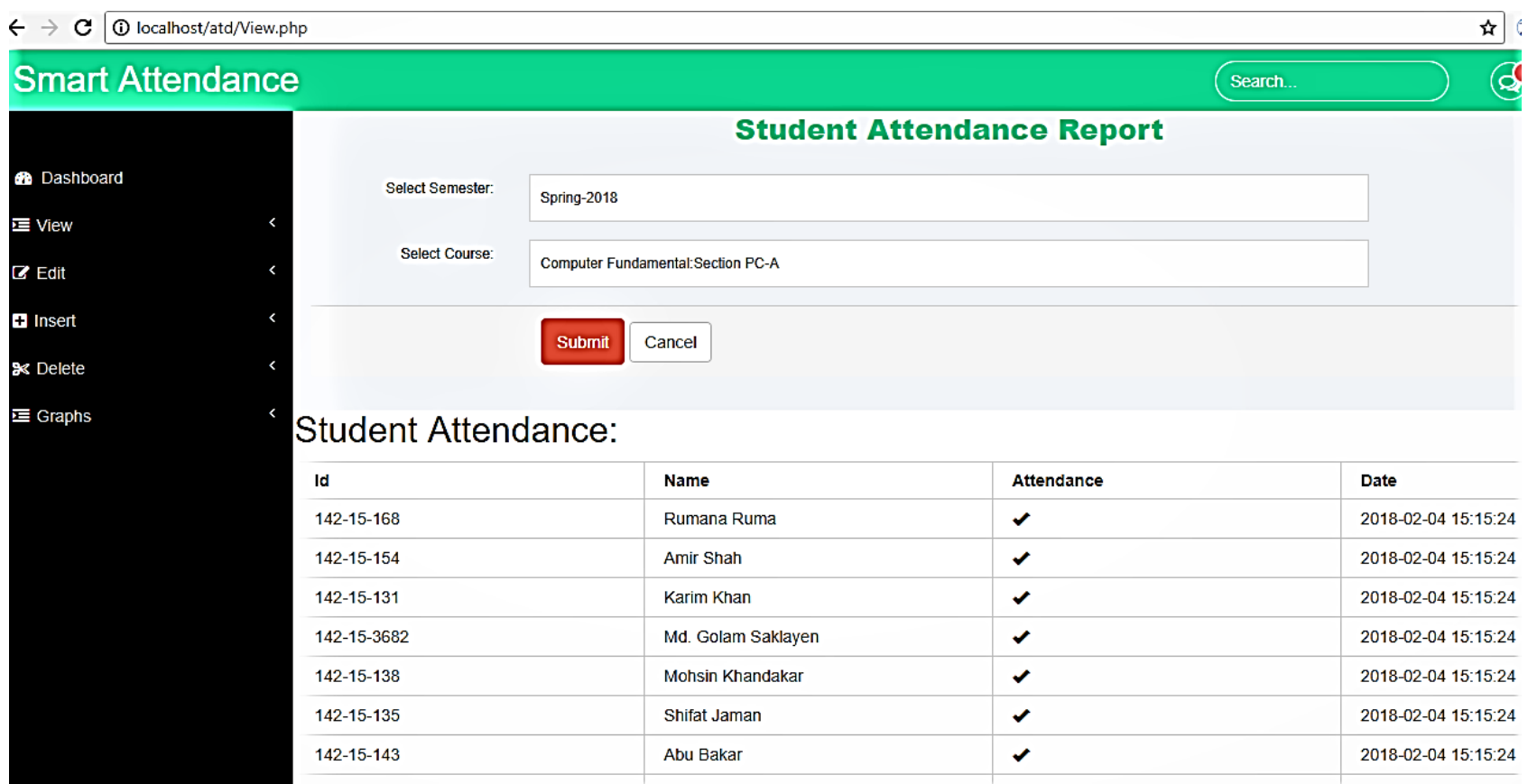

Figure 8. Report of the attendance.

\section{Conflicts of Interest}

The authors declare no conflicts of interest regarding the publication of this paper.

\section{References}

[1] Chang, C.H. (2011) Smart Classroom Roll Caller System with IoT Architecture. 
2011 Second International Conference on Innovations in Bio-Inspired Computing and Applications, Shenzhan, 16-18 December 2011, 356-360.

https://doi.org/10.1109/IBICA.2011.94

[2] Gunjan, T., Ramteke, R. and Shete, A.K. (2013) Wireless Fingerprint Based College Attendance System Using Zigbee Technology. International Journal of Engineering and Advanced Technology (IJEAT), 2, 201-203.

[3] Singh, D., Reddy, A. and Kumar, S.S. (2016) IoT-Based Wireless Attendance Management System Using Finger Print Recognition. INROADS-An International Journal of Jaipur National University, 5, 21-29. https://doi.org/10.5958/2277-4912.2016.00074.6

[4] Prince, N., Sengupta, A. and Unni, M. (2016) Implementation of IoT Based Attendance System on a Dedicated Web-Server. International Journal of Scientific \& Engineering Research, 7, 351-355

[5] Kawaguchi, Y., Shoji, T., Weijane, L., Kakusho, K. and Minoh, M. (2005) Face Recognition-Based Lecture Attendance System. The 3rd AEARU Workshop on Network Education, Tokyo, 2005, 70-75.

[6] Subramaniam, H., Hassan, M., et al. (2013) Bar Code Scanner Based Student Attendance System (sas). Jurnal TICom, 1, No. 3.

[7] Younis, M.I., Al-Tameemi, Z.A., Ismail, W. and Zamli, K.Z. (2013) Design and Implementation of a Scalable Rfid-Based Attendance System with an Intelligent Scheduling Technique. Wireless Personal Communications, 71, 2161-2179.

https://doi.org/10.1007/s11277-012-0929-3

[8] Cho, Y.S. and Kim, K.M. (2015) Nfc-Based Attendance Checking System for Institutions of Higher Education. KIISE Transactions on Computing Practices, 21, 283-289. https://doi.org/10.5626/KTCP.2015.21.4.283

[9] Gopala, K.V.B., Sekhar, S.C., Babu, N.R. and Ravi, K.S. (2012) The Design of Intelligent Campus Security \& Attendance System Based on RFID, GSM and Zig-Bee. 2250-3021.

[10] Yadav, D.K., Singh, S., Pujari, S. and Mishra, P. (2015) Fingerprint Based Attendance System Using Microcontroller and Labview. International Journal of Advanced Research in Electrical, Electronics and Instrumentation Engineering, 4, 5111-5121. https://doi.org/10.15662/ijareeie.2015.0406029

[11] Kavitha, G. and Sankara, K. (2018) Design and Implementation of Smart Attendance System using Raspberry Pi. International Journal of Scientific Research in Computer Science, Engineering and Information Technology, 3, 26-33.

[12] Monk, S. (2015) Programming the Raspberry Pi: Getting Started with Python. TAB Electronics, New York.

[13] Maksimović, M., Vujović, V., Davidović, N., Milošević, V. and Perišić, B. (2014) Raspberry Pi as Internet of Things Hardware: Performances and Constraints. Design Issues, 3, 8.

[14] Ruiyan, C.A.I. (2012) Principle and Application of Arduino. Electronic Design Engineering, 16, 047. 